\title{
A rapid scoping review of fear of infertility in Africa
}

\author{
Jacky Boivin ${ }^{1 *}$ (D) Judith Carrier ${ }^{2}$, Joseph Mumba Zulu ${ }^{3}$ and Deborah Edwards ${ }^{2}$
}

\begin{abstract}
Background: Fear of infertility ( $\mathrm{FOI}$ ) is often reported in studies about reproductive health but this literature not yet mapped. The aim of this rapid scoping review of qualitative studies was to describe the nature of FOI in Africa.

Methods: Eligibility criteria were qualitative data from Africa reporting views of women and men of any age. MEDL INE and CINAHL databases were searched for English language citations to February 2019 using keywords related to fear, infertility and Africa. Two independent reviewers screened texts for inclusion.

Results: Of 248 citations identified, 38 qualitative and six review papers were included. FOI was reported in diverse groups (e.g., men, women, fertile, infertile, married, unmarried, teachers, religious leaders). Two types of fears were identified: (1) fear of triggering infertility due to specific reproductive choices and (2) fear of the dire future consequences of infertility. Choices were perceived to affect fertility via internal accumulation and blockage (e.g., of menstrual blood), structural damage (e.g., burnt eggs), internal movement of contraceptive material, deliberate toxicity preventing population growth and behavioral effects impeding sexual activity. Diverse feared consequences of infertility were reported (e.g., polygamy, economic hardships). Fears were reported to affect reproductive behaviour (e.g., stopping contraception), help-seeking and social behaviour.

Conclusion: $\mathrm{FOl}$ is a phenomenon that should be studied in its own right. Fears could originate from genuine threats, incorrect knowledge, distortions of truths, or dissemination of false information. Rigorous studies are needed to better understand FOI and integrate it in health education, client counselling and family planning service provision.
\end{abstract}

Keywords: Infertility, Health education, Family planning service provision, Counselling, Qualitative research

\section{Plain English summary}

Parenthood is one of the most desired and valued goals of adulthood. Due to this importance some past studies in Africa have reported that people fear having fertility problems, known as fear of infertility. Not much is known about who reports fear of infertility, what the fear is about or how it affects health behaviours. To learn more about it we searched databases and identified studies in Africa providing descriptions of fear of infertility from men and women. In total 44 published records

\footnotetext{
* Correspondence: boivin@cardiff.ac.uk

'School of Psychology. College of Biomedical and Life Sciences, Cardiff University, 70 Park Place, CF10 3AT Cardiff, Wales, UK

Full list of author information is available at the end of the article
}

were examined in detail and summarised. The results showed that fear of infertility was reported by many groups (e.g., married, unmarried, fertile or not, doctors, teachers, religious leaders, men, women). Fear presented itself in two ways. First, people feared triggering infertility because of the choices they made for example, using a particular type of family planning or having certain vaccinations. Many reasons were given for why choices might affect fertility (e.g., damaging insides, accumulation of blood). Second, people feared the dire consequence of being infertile for example, being excluded from their communities or divorced by husbands or wives. Fears were reported to affect health behaviour, for example, not using family planning properly or doing

(c) The Author(s). 2020 Open Access This article is licensed under a Creative Commons Attribution 4.0 International License, which permits use, sharing, adaptation, distribution and reproduction in any medium or format, as long as you give appropriate credit to the original author(s) and the source, provide a link to the Creative Commons licence, and indicate if changes were made. The images or other third party material in this article are included in the article's Creative Commons licence, unless indicated otherwise in a credit line to the material. If material is not included in the article's Creative Commons licence and your intended use is not permitted by statutory regulation or exceeds the permitted use, you will need to obtain permission directly from the copyright holder. To view a copy of this licence, visit http://creativecommons.org/licenses/by/4.0/. The Creative Commons Public Domain Dedication waiver (http://creativecommons.org/publicdomain/zero/1.0/) applies to the data made available in this article, unless otherwise stated in a credit line to the data. 
treatments that could cause more harm to fertility. The review concluded that fear of infertility was a real phenomenon that should be studied in its own right, that education should be provided to address fears and that more research should be conducted on why it existed.

\section{Background}

Fear is an expectation of negative outcomes that is constructed from a complex interplay of physical, psychological, social and cultural relations [1]. One fear that is reported as impacting reproductive choices globally is fear of infertility (FOI), a fear associated with a future inability to achieve pregnancy or father a child [2-4]. Fear of Infertility often presents in the context of decisionmaking about family planning or other health choices affecting reproductive organs (e.g., cervical screening) [3-5]. Fear of infertility is critical to understand and address because it is often unfounded [2], persists from adolescence to adulthood and can have adverse effects on health [3, 6-8]. Fear of infertility is strongest where childlessness is most stigmatised, in rural areas of lowest functional and health literacy [4] and where childlessness is associated with severe consequences especially for women $[9,10]$. The research referring to FOI has not yet been mapped.

A scoping rapid review approach was chosen and performed according to established methods [11]. A rapid review provides high-quality evidence and knowledge synthesis using a stream-lined review process (e.g., searching fewer databases, restricted search timeframe, omitting critical appraisal) [12]. We focused on synthesis of qualitative studies as the design most likely to generate data that would describe FOI and its nature. This approach was selected to achieve the mapping process within the project timeframe of 3 months. We focused on Africa because this review was part of a programme of activities relating to infertility in Zambia prioritised by the Ministry of Health to support integration of fertility care in reproductive health policy and services. The programme of research was developed via face-to-face discussions with academics, healthcare professionals and policymakers who helped identify and prioritise the infertility research strands, outcomes and dissemination strategies. In this programme we also conducted drawing workshops with young married and unmarried women.

\section{Review aim}

The aim of this review of qualitative studies was to map and describe main concepts related to FOI from the perspectives of men and women in African countries.

\section{Main text \\ Methods \\ Inclusion criteria}

This review considered studies that: (1) referred to or explored FOI and what the fears concerned or affected; (2) provided views of women and men of any age from African countries, and; (3) had a qualitative design including mixed methods designs where qualitative data could be extracted separately. Ethical review was not required. The project proposal and all study materials will be available through Open Science Framework (link to be inserted after review). Studies were excluded if they did not explore either 'fear' of triggering infertility or 'fear' of consequence of infertility. Non-African countries were excluded as were quantitative papers.

\section{Search strategy}

MEDLINE (on the OVID platform) and CINAHL (on the EMBSCO platform) were searched for English language citations for published material from database inception to February 2019 using keywords fear AND infertil* OR childless* OR infecundity OR subfecundity AND Africa* OR list of names of all African countries. A separate search was conducted using the term contraceptive OR family planning AND terms for infertility (see Additional file 1 Search History). The reference list of all included studies was screened for additional studies. Medline and CINAHL were chosen as they are the main recommended databases for sourcing relevant studies when conducting a rapid review.

\section{Study screening and selection}

Citations were loaded into Endnote and duplicates removed. Two independent reviewers screened titles, abstracts and full texts of potentially relevant studies using a pre-piloted screening tool designed for the study. Any disagreements were resolved through discussion.

\section{Data extraction}

Data extracted were participant demographic characteristics (e.g., region and country, participants, age), study aims, recruitment, design, questions that elicited FOI data, findings related to FOI, nature of specific fears and reported consequences of FOI. Extraction was conducted by one reviewer and checked by a second. Only data with relevance to FOI were extracted.

\section{Assessment of methodological quality}

An assessment of methodological quality was not conducted which is consistent with accepted scoping review methods [11]. 


\section{Presentation of data}

Data were extracted into tables and a narrative summary provided. For the demographic characteristics data were tabulated using the following headings: region and country, participants and recruitment, methods of data collection, age, ethnicity and religion. A narrative summary accompanies the tabulated results describing how the results related to the review objectives and question. The Preferred Reporting Items for Systematic Reviews and Meta-Analyses Extension for Scoping Reviews (PRIS MA_SCr) checklist has been followed for the reporting of this review (see Additional File 2 PRISMA_SCr).

\section{Results}

\section{Study inclusion}

Figure 1 shows the PRISMA flow diagram for study selection process. Of 248 citations identified, 64 full-text studies were assessed for eligibility and a total of six review papers and 38 qualitative and mixed methods papers (representing 37 studies) were included. Twenty full-text studies did not meet the inclusion criteria (listed in Additional File 3 Excluded studies).

\section{Characteristics of the included studies \\ Phenomena of interest}

Review of included studies showed two types of fears were reported: (1) fear of triggering future infertility due to specific reproductive or health choices (hereafter 'triggering infertility' studies), and; (2) fear of the dire consequences of infertility should one prove unable to demonstrate fertility (hereafter 'infertility consequences' studies).

The characteristics of individual studies are reported in Tables 1 and 2 (respectively) and of review studies (which could concern both types) in Table 3.

For 'triggering infertility', 21 studies and 4 review papers (see Tables 1 and 3) reported on FOI associated with using modern contraceptive methods, one paper each discussed FOI and cervical screening [5], uptake of human papillomavirus (HPV) vaccinations [25], use of human immunodeficiency virus (HIV) prevention products [17]; three further studies explored the link between FOI and abortion [6-8]. For 'infertility consequences' there were 16 studies (across 17 publications) and two review papers with relevant data (see Tables 2 and 3).

The following text summarises key study characteristics from Tables 1 to 3 .

\section{Study design}

The majority of studies $(n=19)$ described the methodology as solely qualitative descriptive $[5,7,8,13,18-24$, $26,27,31,35-40]$ or qualitative combined with other methods ( $n=11$ studies) in mixed methods research projects $[6,10,14-17,29,30,32-34]$. Other qualitative studies were anthropological $(n=2)$ [42, 43], ethnographical $(n=3)[28,44,45]$ and phenomenological $(n=$ 1) $[41]$ designs.

\section{Country of origin}

The countries of origin primarily included Ghana $(n=8)$ $[5,13,29,31,35,38-40]$, Kenya $(n=4)[5,26,29,41]$, Uganda $(n=3)[14,19,20]$, Tanzania $(n=3)[25,28,34]$, South Africa $(n=3)[24,32,36]$; Cameroon $(n=2)[8,43]$, Mozambique $(n=2)[15,42]$, Mali $(n=2)[18,33]$ and Nigeria $[6,7]$. One research study was also conducted in each of the following countries Madagascar [27], Congo [22], Ethopia [16], Malawi [45], Rwanda [30], The Gambia [10], Zimbabwe [37] and Botswana [44]; and one across Malawi, South Africa, Uganda and Zimbabwe [17]. See Fig. 2 for number of studies across African countries.

\section{Participants}

In the 'triggering infertility' studies, the participants included female $[5,13,16,20,22,23,29]$ and male $[5,13$, $16,20,22,23,25,29]$ participants, adolescent boys [15, 18, 19, 29] and girls [15, 18, 19, 29]. Participants were described as: being married [16], married with children $[22,23]$, and women that were sexually active $[7,17,26]$ or not [7], with experience of pregnancy [14, 21, 22, 24, 28] having had an abortion [8], fertility problems [6], having had or not cervical screening [5], or students attending local schools [25, 27]. Nine studies additionally reported views of traditional healthcare professionals $[23,25,27]$, health workers [23, 25, 27-29] community leaders [13, 28, 29], religious leaders [25, 27, 29], peer educators [18], family planning service providers [20], aid workers [27], policy workers [20], teachers [25, 29], parents [25].

Participants in the 'infertility consequences' studies were couples $(n=3)[30,38,39]$, women $(n=9)[10,31-$ $35,41-43]$, men $(n=2)[40,45]$ or combination thereof $(\mathrm{n}=3)$ [36, 37, 44] Also represented were traditional healthcare professionals or healers [38, 39, 42], religious leaders [38, 39] and managers of insurance schemes [38, 39]. Participants were described as having fertility problems (diagnosed or not, in treatment or not) $(n=12)[10$, $30-34,37,40-44]$ seeking treatment in gynaecological and obstetric clinics $(n=1)$ [35] or being childless $(n=3)$ $[38,39,45]$. Three studies also explored the perspectives of fertile women $[34,42,44]$.

\section{Types of questions from which FOl data emerged}

Among 'triggering infertility' studies FOI data was reported to emerge from questions about family planning $[13,15$, $21,24,27,28]$ opinions thereof [19, 24, 27], barriers to use $[18,22,26,28,29]$, knowledge of family planning [26, 28], side effects [29] and sources of influences [28]. Two studies asked specific questions about FOI $[18,29]$. Aside from 


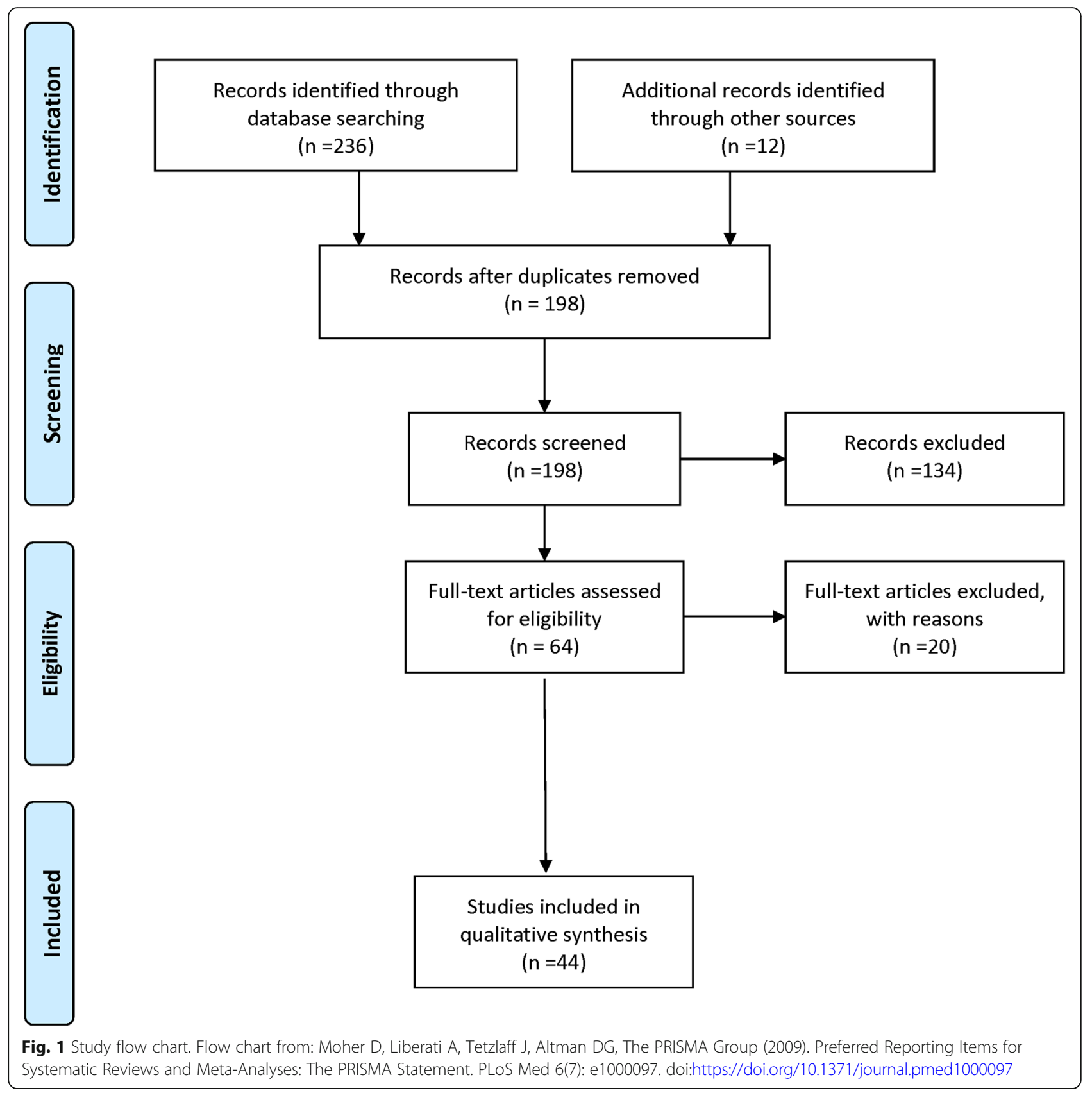

family planning, one study each explored the reasons for not wanting cervical cancer screening [5], HPV vaccination and its barriers [25] and abortion [14].

In 'infertility consequences' FOI data was reported to emerge from questions about infertility in the following domains: social $(n=7)[10,30,32,34,35,40,41]$, emotional/psychological $(n=5)[10,30,37,40]$, economic $(n=1)$ [30], cultural and belief systems $(n=4)$ [30, 34, $37,41]$ or personal experiences $(n=7)[10,33-36,41$, 44]. Only one study asked questions about feared consequences specifically [44].
Questions were not provided for one study on HIV prevention [17], five publications on infertility consequences [31, $38,39,42,45]$ and two studies exploring both topics [6-8]).

\section{Mapping of research findings about fears}

Fears in 'triggering infertility' studies

A fear presented across all included studies was that infertility could be triggered by using modern family planning methods [3, 4, 7, 8, 13-16, 18-21, 23, 24, 26-29, 46, 47]. This fear was expressed as permanent sterility or infertility $[4,6-8,18,22,24,26,28,46]$, temporary or delayed fertility 
Table 1 Characteristics of included studies related to 'triggering infertility'

\begin{tabular}{lll}
\hline Author/s & $\begin{array}{l}\text { Methods of data collection } \\
\text { Region, Country }\end{array}$ & $\begin{array}{l}\text { Focus of study } \\
\text { Participants and Recruitment }\end{array}$ \\
\hline
\end{tabular}

\section{a) Qualitative descriptive part of a mixed methods study}

1.Dalaba et al. 2016 [13]

Kassena-Nankana, Ghana

2. Morse et al. 2012 [14]

Kampala, Uganda

3. Capurchande et al. 2016 [15]

Ndlavela \& Boane, Mozambique

4. Gebremariam and Addissie 2014 [16]

Adigrat town \& Tigray, Ethiopia

5. Koster 2010 [6]

Yoruba, Nigeria

\section{b) Qualitative descriptive part of a randomised control trial}

6. Chituka et al. 2019 [17]

Lilongwe (Malawi); Cape Town, Durban, Johannesburg (South Africa); Kampala (Uganda); Harare (Zimbabwe)

\section{c) Qualitative descriptive}

7. Castle 2003 [18]

Barnako \& Sikasso, Mali

8. Cover et al. 2017 [19]

Gulu District, Uganda

9. Hyttel et al. 2012 [20]

Mbarara \& Kampala, Uganda

10. Krugu et al. 2017 [21]

Bolgatanga, Ghana

11. Muanda et al. 2016 [22]

Kinshasa, DRC

12. Adongo et al. 2014 [23]

SBAB \& KEEA, Ghana

13. Ndwamato

and Ogunbanjo 2009 [24]

Limpopo Province, South Africa

14. Otoide et al. 2001 [7]

Benin City, Nigeria
Focus groups $(n=16)$ with men and women $(n=\mathrm{ns})$ from community-based health planning \& services

Interviews with community Chiefs and Elders $(n=8)$

Focus groups $(n=10)$ with pregnant women $(n=46)$ presenting for prenatal care at local hospital

Focus groups $(n=4)$; interviews $(n=16)$, informal conservations ( $n=4)$; Observations with adolescents and young adults ( $F: n=23, M: n=19$ ) selected from respondents to wider community survey

Focus groups ( $n=5)$ with married men and women ( $n=\mathrm{ns}$ ) selected from wider community survey and interviews with FP service providers $(n=6)$ selected from HCPs in local health centres

Interviews with women with fertility problems $(n=223)$ who had completed a community survey or those who had participated in the development of the survey

Single Interviews $(n=34)$, serial interviews at 3 months, 6 months and product end $(n=80)$ and focus groups

( $n=100$ participants) with healthy sexually active HIV-negative women $(n=214)$

Interviews with adolescent ( $M: n=10, F n=10)$ from peer education programs, adolescents (M: $n=10, F: n=10)$ from community, peer educators (M: $n=10, F n=10)$; HCPs (M: $n=4 \mathrm{~F} n=4)$

Interviews with adolescent women $(n=46)$ from an outreach clinic and youth centre

Interviews (F: $n=28 ; M: n=18$ ) recruited while waiting for health services, while attending NGO activities, identified by Reproductive Health Uganda peer educators or randomly from their villages

Focus groups ( $n=3$ ) with FP service providers $(n=17)$ working across public and private sectors, policymakers $(n=15)$ selected from organizations and snowball sampling

Interviews with young women who have experienced pregnancy $(n=20)$ recruited through advertisements in public buildings, including schools and health or by nurses at local health centres

Focus groups ( $n=10$ ) with women and their husbands who had at least two children $(n=n s)$ recruited from private and public health centres

Focus groups ( $n=21)$ with men $(n=\mathrm{ns})$ and Women $(n=\mathrm{ns})$ married with children from the community

Interviews with $\mathrm{CH}$ officers; $\mathrm{HC}$ volunteers and HCM from the community

Focus groups ( $n=5)$ with multiparous women $(n=\mathrm{ns})$ seen at a local hospital

Focus groups ( $n=20)$ with women $(n=149)$ who were sexually active \& those who had not initiated sexual activity who were selected on the basis of their current vocation or pursuit within Benin City
Hormonal contraceptives

$>35$ or $<35$

General contraception and FP $<20(n=7) / 21-25(n=19)$ $26-30(n=11) />30(n=9)$

General contraceptive methods Range 15-24

LAPCM

Range 15-49

Abortion

Range 15-49

Vaginal ring

Mean 26.4

Range 14-42

Hormonal contraceptives

Range 15-19

Contraceptive self injection Range 15-19

Injectable hormonal contraceptives F; $18-29(n=9)$ / F: 30-45 $(n=19)$ M: 18-29 ( $n=9)$ / M: 30-60 ( $n=9)$

General contraception and FP

Range 14-19

General contraception and FP 20-34 (married); 15-19 (unmarried)

General contraceptive methods Not reported

General contraception and FP Not reported

Abortion

Range 15-24 
Table 1 Characteristics of included studies related to 'triggering infertility' (Continued)

\begin{tabular}{|c|c|c|}
\hline $\begin{array}{l}\text { Author/s } \\
\text { Region, Country } \\
\end{array}$ & $\begin{array}{l}\text { Methods of data collection } \\
\text { Participants and Recruitment }\end{array}$ & $\begin{array}{l}\text { Focus of study } \\
\text { Age (years) }\end{array}$ \\
\hline $\begin{array}{l}\text { 15. Schuster } 2005[8] \\
\text { Anglophone, Cameroon Grassfields }\end{array}$ & $\begin{array}{l}\text { Interviews and participant observation with women who had } \\
\text { come to the hospital for treatment of complications of unsafe } \\
\text { abortion or who had an induced abortion in their history } \\
(n=58) \text { identified through medical records and women who } \\
\text { had had an abortion and had not been hospitalised identified } \\
\text { through a snowball sample }(n=7) \text {. Interviews with key } \\
\text { informants ( } n=n s)\end{array}$ & $\begin{array}{l}\text { Abortion } \\
\text { Not reported }\end{array}$ \\
\hline $\begin{array}{l}\text { 16. Lunsford et al. } 2017 \text { [5] } \\
\text { Nairobi \& Nyanza, Kenya }\end{array}$ & $\begin{array}{l}\text { Focus groups }(n=10) \text { with women }(n=60) \text { and their partners } \\
(n=40) \text { who had received cervical cancer screening }(n=60) \\
\text { and those who did not }(n=40) \text { recruited from health care and } \\
\text { community forums }\end{array}$ & $\begin{array}{l}\text { Cervical screening } \\
\text { Range 25-49 }\end{array}$ \\
\hline $\begin{array}{l}\text { 17. Remes et al. } 2012 \text { [25] } \\
\text { Mwanza Region \& Misungwi, Tanzania }\end{array}$ & $\begin{array}{l}\text { Focus groups }(n=12) \text { and interviews with female students } \\
(n=54) \text { from local schools, teachers }(n=19) \text {; Parents }(n=59) \text {, } \\
\text { health workers }(n=9) \text {, religious leaders }(n=9)\end{array}$ & $\begin{array}{l}\text { Vaccination } \\
\text { Students: } 11-17\end{array}$ \\
\hline
\end{tabular}

\section{d) Ethnographic studies}

18. Ochako et al. 2015 [26]

Kismu, Mombasa \&, Thika, Kenya

19. Klinger and Asgary 2017 [27] Anivorano Nord, Ambondromifehy, Marotaolana, and Beanemalao; Madagascar

20. Chebet et al. 2015 [28]

Morogoro Region, Tanzania

21. Sedlander et al. 2018 [29]

Kilifi County, Kenya

\begin{abstract}
Interviews with sexually active women both users $(n=20)$ and non-users of contraceptives $(n=11)$ purposively selected from the community

Focus groups ( $n=7$ ) with adolescents (F: $n=23 / \mathrm{M}: n=20$ ) residing in or attending local schools

Interviews with those in each of the four villages who were involved with providing medical care or education to the youth in the village (Physician F: $n=1$, Midwives F: $n=2$, $\mathrm{CH}$ Workers $n=2)$ \& Aid workers $(n=2)$

Interviews with postpartum women $(n=34)$, their partners $(n=23)$, community leaders $(n=12)$; $\mathrm{CH}$ leaders $(n=19)$; Facility health providers $(n=12)$ recruited from local communities
\end{abstract}

Focus groups ( $n=32$ ) with men, women, adolescent boys and girls $(n=153)$ and interviews with village chiefs and elders, pastors, teachers, health care workers $(n=10)$ from the community.
General contraception and FP $16-19(n=13) / 20-24(n=11)$

General contraceptive methods Range 15-19

General contraceptive methods F: Mean 28.56 / F: Range 18-43

General contraception and FP Mean 26.2 / Range 13-65

Key: $C H$ community health; DRC Democratic Republic of Congo; $F$ female; FP family planning; $H C M$ health care managers; $H C P$ Health care providers; KEEA Komenda-Edina-Eguafo-Abrem; $L A P C M$ Long acting and permanent contraceptive methods; M Male; SBAB Sefwi Bibiani-Ahwiaso Bekwai. Reference citation follows author name in square brackets

$[14,20,26,28]$ or fertility not returning once contraception was stopped $[14,16]$. These reports were in relation to hormonal methods (oral and injectable) $[4,6,7,14,18-20,23$, $24,26]$ and long acting and permanent contraceptive methods such as intrauterine devices or implant [3, 6, 1416, 23, 24]. Only one review paper [47] cited a study that reported a link between FOI and condom use.

Fear of infertility was also reported in relation to abortion; women feared that unsafe methods could leave women infertile [6-8] and some condemned the use of induced abortion because of FOI [14]. Future infertility was also cited as a possible consequence of cervical cancer screening uptake [5], HPV vaccination of primary school girls in Tanzania [25] and use of the vaginal ring as an HIV prevention product [17].

\section{Explanations for fears in 'triggering infertility' studies} Fourteen studies and three of the review papers provided detailed descriptions of why reproductive or health choices were perceived to affect fertility (see Additional file 4 Explanations).

\section{Accumulation and blockage}

Women believed that oral contraceptive pills stayed in the womb and accumulated $[18,28]$; men believed they spread throughout the body [28] or blocked up the reproductive organs [18]. A perceived consequence of hormonal contraceptives was too much or too little bleeding which was seen as affecting fertility [18]. Self-injection were associated with excessive bleeding accumulating in the womb [19, 23]. Pills and self-injections were perceived to prevent pregnancy through blocked blood $[15,46]$ or a blocked uterus [18, 28, 29].

\section{Structural damage}

There was a belief that ovarian damage could be caused by the HPV vaccine [25], contraceptive self-injection [19], intrauterine device (IUD) [14] or family planning in 
Table 2 Characteristics of included studies related to "infertility consequences"

\begin{tabular}{lll}
\hline Author/s & Methods of data collection & Age (years) \\
Region, Country & Participants and Recruitment &
\end{tabular}

\section{a) Qualitative descriptive part of a mixed methods study}

1.Dhont et al. 2011 [30]

Kigali, Rwanda

2.Donkor et al. 2017 [31]

Accra, Ghana

3.Dyer et al. 2002 [32]

South Africa

4. Hess et al. 2018 [33]

Koutiala, Mali

5.Dierickx et al. 2018 [10]

West Coast region, The Gambia

6.Hollos and Larsen 2008 [34]

Moshi, Tanzania

\section{b) Qualitative descriptive studies}

7. Fledderjohann 2012 [35]

Accra, Ghana

8. Mabasa 2005 [36]

South Africa

9. Runganga et al. 2001 [37]

Harare, Zimbabwe

\section{Tabong}

Upper West Region, Ghana

11. Naab and Kwashie 2018 [40]

Ghana and Adongo 2013a/b [38, 39]

Focus group discussions ( $n=5$ ) with couples ( $F: n=21 / \mathrm{M}: n=20$ )

with infertility problems being offered investigations at an Infertility clinic

Interviews with women $(n=14)$ receiving treatment for infertility problems at a local hospital

Interviews with women $(n=30)$ receiving treatment for infertility problems at an infertility clinic

Interviews with infertile women $(n=26)$ attending a hospital infertility clinic

Interviews with infertile women $(n=33)$ from the local community

Interviews with infertile $(n=25)$ and fertile women $(n=25)$ from the local community

Interviews with women $(n=107)$ seeking treatment in gynaecological and obstetric clinics

Interviews with infertile couples $(n=10)$ and infertile women $(n=9)$ selected through researchers' networks and snowball sampling

Focus group discussions $(n=9)$ and interviews with women $(n=8)$ and men $(n=2)$ attending a fertility clinic for reproductive problems

Focus groups ( $n=n s)$ and interviews with childless couples $(n=15)$ selected by $\mathrm{CH}$ volunteers and snowball sampling and gynaecologists $(n=2)$; Islamic scholar $(n=1)$; Christian leader $(n=1)$; traditional medical practitioners $(n=2)$; manager of NHIS $(n=1)$; manager PIC $(n=1)$

Interviews with married men $(n=12)$ receiving treatment for infertility at a local hospital

Interviews with infertile women $(n=10)$ attending local churches

12. Kamau 2012 [41]

Nairobi Province, Kenya

\section{d) Anthropological studies}

13. Gerrits 1997 [42]

Montepuez, Mozambique

14. Feldman-Savelsberg 1994 [43] Bangangte, Cameroonian Grassfields

\section{e) Ethnographic studies}

15. Upton and Dolan 2011 [44]

Northern Botswana

16. Parrott 2014 [45]

Karonga District, Malawi
Interviews with infertile $(n=34)$ and fertile women $(n=10)$ from the local community and traditional healers $(n=3)$; midwives $(n=3)$; physicians $(n=2)$; nurses $(n=3)$

Narrative with infertile women (no further details provided)

Ethnographic narratives with men $(n=20)$ and women $(n=31)$ who were married, unmarried, fertile and those identifying to have struggled with fertility problems selected from local community

Life history interviews with men who had experienced childless marriages $(n=55)$ selected from a wider community survey not reported

F: Mean 28.5 /

Range 27-33

M: Mean 34.5 /

Range 30-40

Range 27-42

Mean 31.5 /

Range 21-41

Mean 17-44

$>18$

Range 20-44

Mean 33

Range 21-48

Mean 36.9

Range 25-48

Mean 30

Range 21-40

F: Range 28-52

M: Range 35-63

$>25$ years

Range 29-41

Mean 40.4

Range 29-54

Range 19-50

not reported

not reported

Key: CH Community health; F Females; M Males. NHIS National Health Insurance Scheme; PIC Private Insurance company. Reference citation follows author name in square brackets

general [28]. Family members thought that the HPV vaccine acted to "disorder and destroy the eggs" [25].pg.5635. Women and religious leaders used terms such as "burns eggs" [28]. pg.6 "wasted eggs" or "kills God's eggs" [28] p.8 for effects of hormonal contraceptives. [Repeated] abortions at a young age [8] or using hormonal contraceptives were thought to damage or spoil the womb [29, 46]. Women, men and healthcare providers believed modern contraceptive methods affected fertility by causing the womb to become "weak" [29].pg.350, "thin [29].pg.351" or "tired" [46] pg.10. Women with fertility problems thought that having an abortion would spoil 
Table 3 Characteristics of included review articles

\begin{tabular}{|c|c|c|c|}
\hline Author & Type of review & Country & Focus \\
\hline 1.Polis et al. 2018 [46] & Scoping review & Africa (11\%) & $\begin{array}{l}\text { Women's responses to contraceptive-induced } \\
\text { menstrual bleeding changes }\end{array}$ \\
\hline 2.Ackerson and Zielinski 2017 [47] & Narrative review & Sub-Saharan Africa & $\begin{array}{l}\text { Factors that inhibit or promote family planning } \\
\text { and contraceptive use }\end{array}$ \\
\hline 3.Dyer and Patel 2012 [48] & Systematic evaluation & $\begin{array}{l}\text { Developing countries } \\
\text { Africa }(n=13)\end{array}$ & Out-of-pocket payment for infertility care \\
\hline 4.Daniele et al. 2017 [3] & Systematic review & $\begin{array}{l}\text { Low- and middle-income countries } \\
\text { Including Africa }\end{array}$ & $\begin{array}{l}\text { Provider and lay perspectives on intra-uterine } \\
\text { contraception }\end{array}$ \\
\hline 5.Williamson et al. 2009 [4] & Systematic review & $\begin{array}{l}\text { Developing countries } \\
\text { Sub-Sahara Africa }(n=6)\end{array}$ & $\begin{array}{l}\text { Limits to modern contraceptive use identified } \\
\text { by young women }\end{array}$ \\
\hline 6.van Balen and Bos 2009 [9] & $\begin{array}{l}\text { Literature review } \\
\text { with adapted IPA }\end{array}$ & $\begin{array}{l}\text { Poor resource areas } \\
\text { Sub-Sahara Africa }(n=19)\end{array}$ & Social and cultural effects of being childless \\
\hline
\end{tabular}

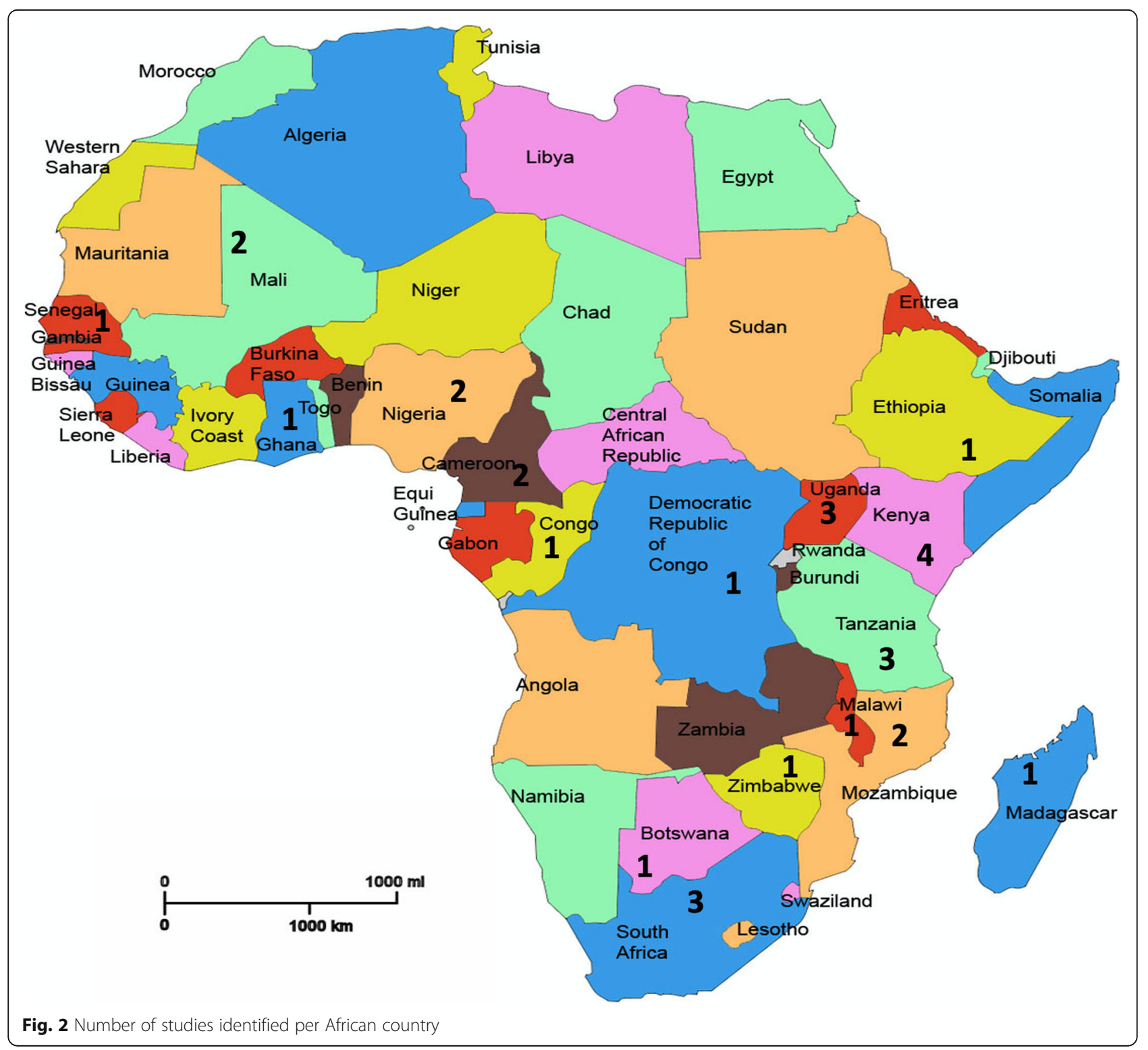


or destroy the womb [6]. Adolescent peer educators believed that the oral contraceptive pill worked by stopping implantation rather than ovulation [18]. Men, women and religious leaders reported that hormonal contraceptives killed [18, 28] or neutralized sperm [18].

\section{Internal movement of contraceptive material}

Pregnant women feared that the IUD would cause damage to nearby organs [14] or may go missing [13] which would result in the need for an operation that could affect future fertility. Men thought the IUD resulted in internal complications for young girls because their uterus was not developed [29]. Others thought the IUD would pass through the vagina into the womb [23] or that condoms would remain inside the body [46] therefore leaving women infertile. Women thought that the internal use of the speculum for cervical screening would cause infertility but did not elaborate on the specific mechanism [5].

\section{Deliberate toxicity and contamination}

There was a widespread belief among participants of a study on the vaginal ring for HIV prevention that the drugs inside the ring had been put there to deliberately cause infertility "to limit the Black population" [17]' p6. Men and women said that oral contraceptive pills or selfinjections entered the blood stream and intentionally contaminated the blood $[7,18]$ or infiltrated blood to "kill all the germs that cause ovulation"pg. 193 [32].

\section{Behavioral effects impeding sexual activity}

Women experiencing vaginal dryness when using hormonal contraceptives reported it caused a loss of libido contributing to their inability to achieve pregnancy [20]. Others believed that the husband could be harmed during sex if the women used an IUD, also leading to childlessness [3].

\section{Fears in 'infertility consequences' studies}

Sixteen studies (across 17 publications) and three review papers reported on the feared consequences of infertility (see Additional file 5 Consequences).

\section{Fears of marital / partnership disruption}

Men feared disapproval from their families and women feared partners would leave them when couples remained childless after cohabitation [36]. Married women feared the marriage would end in divorce [9, 41-43] or infidelity if they did not become pregnant [43]. Infertile men who had previously divorced feared that on becoming married again the next wife would leave them too because of their infertility [45]. Women that were not yet pregnant voiced fear that the husband would take another wife $[9,33]$ because relatives were pressurizing the husband [34]. Similar fears were expressed by childless women having perpetual fear of rivals (co-wives) $[38,39]$ and of tension between wives [10].

\section{Fears of lower social standing}

Wives expressed fear that their husband would listen to relatives and send her away [34] and feared mistreatment by their mother in law [38, 39]. Other childless women feared being isolated and left alone in their life $[33,37]$ or feared not having any true friends [41]. Men who were childless feared being openly insulted and disgraced $[38,39]$ or laughed at [36]. Women feared that an infertility status would label them with derogatory terms for being barren, i.e., "moopa" [44].pg.97. Concerns about their future social status led women to fear being "condemned" [4].pg.111.

\section{Fear of future economic hardships}

Infertile women and men voiced fear of economic difficulties in old age as they would lack the support of children [32] which was considered a daunting prospect [30, 31]. Participants feared losing properties and becoming impoverished [38, 39]; as well as losing financial support [37]. This included their property being taken by others after their death [30] and fear about the day of their funeral in which children play an important role [30].

\section{Other fears}

Men reported unspecified emotions related to fear (e.g., worries/sadness and fear) [40]. Men's fears of sterility over-shadowed fears of HIV/AIDS (Acquired Immune Deficiency Syndrome) [44]. Women feared that witchcraft prevented the doctors from finding a cause for childlessness [32].

\section{Reported consequences of FOI}

Fear of infertility was reported to cause a slow uptake of family planning [28], a switch to different or less effective family planning among adolescents and young women with no history of any fertility problems who had never been pregnant $[15,18]$, for participants to rely on abortion instead of contraception [7], to incorrectly use the vaginal ring [17], to abstain from using family planning methods [22] (e.g., hormonal contraceptives $[18,23,26,29]$, implants [26], injectables [19]), the HPV vaccination [25] and cervical cancer screening [5], or to discontinue use of injectables $[19,20,26]$ and hormonal contraceptives [23]. FOI was reported to cause women to either not use family planning or use it incorrectly to prove their fertility or avoid infertility [6-8].

Regarding attitudes, a belief in the community and community leaders was that due to FOI young women (especially the nulliparous) should not start 
contraception $[14,20,22,28]$ or that injectables should only be recommended for women who already had children [26]. Wives reported that husbands/partners disapproved using family planning because of FOI $[13,21]$ consequently women sometimes used oral contraceptives without informing the husband [22]. Due to the possibility of being seen as at risk for infertility from using contraceptives some women were fearful of going to health centres for family planning [29].

Due to FOI and possible permanent childlessness the behaviour of not-yet fertile and infertile was affected. Among cohabitating couples, men broke promises of marriage if the woman had not produced a child during cohabitation [36]. Sometimes husbands of infertile women took second wives $[30,36,37]$ or were encouraged by family members to abandon childless wives [30]. In the case of male infertility women reported that they would get pregnant through extra marital sex [10, 30, $37,39]$ but that they kept it a secret from their husbands $[30,36]$, though some reported not doing this in case the husband knew of his infertility [36]. Traditional healers and spiritual leaders were consulted when pregnancy was not achieved [32, 33, 36, 39, 41, 45]. Traditional intervention could involve herbs [32, 33, 38], rituals [33, 39], sacrifices [33, 39], casting out of ancestral spirits [36], sexual preparations and remedies [37], therapeutic sex with healers [37] and other traditional fertility enhancement procedures [37]. Fear of infertility was also associated with religious practices (e.g., prayer, fasting) or divine interventions [30, 33, 39, 41, 45]. Men and women sought biomedical treatment $[18,47,49,50]$ but some kept treatment secret [30,37].

Other behavioural consequences for childless or infertile women were relying on alcohol [37, 38]. Some childless couples adopted the children conceived in polygamous relationships [37], looked after the children of others [30, 37], fostered [30] or re-engaged with other goals (e.g., economic) [38].

\section{Country differences}

There were too few studies per country to carry out and in-depth comparison of fears between countries. Available data do not appear to show systematic differences (see Additional files 4 and 5).

\section{Conclusion}

Fear of infertility is a phenomenon that should be studied in its own right. Evidence for FOI was reported in many sub-Saharan African countries and expressed by a wide range of people (e.g., men, women, young people, teachers, healthcare professionals, religious leaders, and the childless). Two types of fears were identified in included qualitative studies: fear that specific health or reproductive choices (e.g., family planning) would trigger future infertility and fear of dire consequences of infertility for oneself. Many explanations were offered for why choices could affect fertility, and many feared consequences described. Fear of infertility was reported to affect behaviour in important ways but was rarely the main topic of the included studies. Rigorous prospective studies are needed to understand origins of FOI, optimise health messaging about FOI and minimise its consequences on health behaviour and outcomes. Integrating fertility in sexual and reproductive health policies could stimulate necessary partnerships where FOI was observed (e.g., family planning, HPV vaccination, HIV prevention, infertile communities) and support de-stigmatisation of infertility, an important precursor of FOI in the community.

Fears were reported to impact behaviour, for example abstaining altogether from using family planning, switching from more to less effective contraception and missing opportunities for prevention (screening, vaccination). Additionally, people fearing the consequences of permanent sterility engaged in health-behaviours that would not resolve fertility problems including some that might have caused or exacerbated fertility problems (e.g., unprotected sex [37]). Despite these reported effects not much importance seems to be placed on FOI in existing research. FOI was the focal study topic in only $5 \%$ of included studies. Even if FOI affected a small proportion, its impact could be significant given suggested effects on behaviour. Estimating prevalence of FOI and determining its impact on behaviour in rigorously designed prospective studies is warranted.

Fears are constructed expectations of negative outcomes [1]. As such FOI could originate in genuine threats (e.g., genuine severe consequences of infertility, unsafe abortion), distorted or poorly understood facts (e.g., delay in return to fertility after injectables) or motivated spread of misinformation (e.g., leaders exhorting malevolent motives of white researchers [2, 17]). How ever constructed, FOI should be explicitly addressed in health education with men and women of all ages making health and reproductive choices [51]. Providers of education (e.g., teachers, community leaders) also reported fears and possibly are transmitters of FOI so they too could benefit from more training about links between fertility and reproductive or health choices (e.g., family planning, screening). It will be more difficult to tackle fear of the dire consequences of infertility as this is likely to require wider societal change to de-stigmatise infertility and childlessness. Although we dealt with the two types of fears separately, we believe these to be causally related. People making choices would fear future infertility less if infertility caused less dire consequences for those affected. Current initiatives to increase understanding and awareness of causes of fertility problems [49], integration of fertility care in sexual and 
reproductive health policy [52] and inclusion of fertility topics in national education curriculums should help. We agree with recent calls for integration at such levels [50] because it would stimulate the necessary partnerships across areas where FOI was observed and strengthen potential for timely research and health education. Future research could also benefit from cross country comparisons to ensure that local beliefs are adequately considered and addressed.

\section{Limitations}

We believe we have mapped the main concepts and topics to emerge from research referring to FOI. However, the search strategy for 'fear' is complicated by the many ways such fears could be expressed (e.g., worry, concern, threat, afraid) and the fact that FOI is not a MeSH (Medical Subject Headings) term. Consequently, the literature on FOI could be much larger (though not necessarily more informative). We used a rapid review scoping method which entails the usual methodological limitations of this approach (e.g., limited search, lack of quality assessment, not all reproductive choices). For example the paper would be excluded if it did not identify fear related to current or future infertility in the abstract, or as a succinct theme heading. This means that some studies that could have indirectly related to effects of fear on infertility could be omitted. We selected only qualitative studies and in so doing we missed the gains that could have been achieved with quantitative data (e.g., proportion of specific populations reporting FOI). We provided a simple thematic account of FOI, but a more in-depth analysis could have provided useful elaboration. For example, we did not pay attention to the development, maintenance, sharing or resolution of FOI but this would be worth investigating in future research [53]. Finally, the two fears seem to occur in different populations, moments in the life span and readiness to achieve pregnancy/father a child. Future reviewers and researchers may choose to deal with one or both fears, but we suggest that causal relations between these should not be ignored.

In conclusion, fear of infertility concerns fear of triggering infertility and fear of the dire consequences of infertility to oneself. Fear of infertility should be addressed and its potential impact on reproductive and health choices the subject of further investigation.

\section{Supplementary information}

Supplementary information accompanies this paper at https://doi.org/10 1186/s12978-020-00973-0.

Additional file 1. Search History_Medline.docx Illustrative Search Strategy

Additional file 2. PRISMA-SCR Checklist.docx PRISMA checklist for scoping reviews
Additional file 3. excluded studies.docx Studies excluded (DOCX $27 \mathrm{~kb}$ )

Additional file 4. Explanations.docx Explanations for why choices affected fertility

Additional file 5. Consequences.docx Feared consequences of infertility

\section{Abbreviations}

AIDS: Acquired immunodeficiency disorder; FOI: Fear of Infertility; HIV: Human immunodeficiency virusIUD = intrauterine device; HPV: Human papillomavirus; MeSH: Medical Subject Headings; PRISMA: Preferred Reporting Items for Systematic Reviews and Meta-Analyses; PRIS MA_SCr: Preferred Reporting Items for Systematic Reviews and MetaAnalyses Extension for Scoping Reviews

\section{Acknowledgements}

Not applicable.

\section{Authors' contributions}

$J B$ and JZ consulted with stakeholders about the research and wrote the grant proposal. JB, JC and DE developed the review protocol. DE performed the search and, with JC, study selection and data extraction. JB, JC, DE synthesised the data and drafted the first version of the manuscript. All authors critically reviewed, discussed and finalised the submitted manuscript, and (will) contribute to all revisions. All authors are aware of each author's role in the review, and agree to be accountable for the work, and to investigate and resolve any issues related to the accuracy or integrity of the work.

\section{Funding}

This project is part of the Economic and Social Research Global Challenges project supporting development of fertility awareness tools in low and middle income countries (ES/M500422/1) and funding from the Higher Education Funding Council for Wales Global Challenges Fund (JA1710RB08). Funders were not involved in any aspect of the review.

\section{Availability of data and materials}

All data generated or analysed during this study are included in this published article [and its supplementary information files].

Ethics approval and consent to participate

Not applicable as this is a review.

Consent for publication

Not applicable as this is a review.

\section{Competing interests}

Outside of submitted work, Prof Jacky Boivin reports: personal fees from Merck KGaA, Merck AB and Ferring Pharmaceuticals A/S for advisory work, speaker fees from Theramex and a research grant from Merck Serono Ltd. Jacky Boivin is co-deputy of the 'Fertility Education Initiative' of the British Fertility Society that aims to improve awareness of fertility and infertility.

\section{Author details}

${ }^{1}$ School of Psychology. College of Biomedical and Life Sciences, Cardiff University, 70 Park Place, CF10 3AT Cardiff, Wales, UK. Wales Centre for Evidence Based Care, School of Health Care Sciences, Cardiff University, Cardiff, Wales, UK. ${ }^{3}$ School of Public Health, University of Zambia, Lusaka, Zambia.

Received: 5 March 2020 Accepted: 3 August 2020

Published online: 14 September 2020

\section{References}

1. Tudor A. A (macro) sociology of fear? Sociol Rev. 2003:51:238-56.

2. Kayler A. Health interventions and the persistence of rumour: the circulation of sterility stories in African public health campaigns. Soc Sci Med. 2009;68: 1711-9.

3. Daniele M, Cleland J, Benova L, Moazzam A. Provider and lay perspectives on intra-uterine contraception: a global review. Reprod Health. 2017;14.

4. Williamson LM, Parkes A, Wight D, Petticrew M, Hart G. Limits to modern contraceptive use among young women in developing countries: a systematic review of qualitative research. Reprod Health. 2009;6. 
5. Lunsford N, Ragan K, Lee Smith J, Saraiya M, Aketch M. Environmental and psychosocial barriers to and benefits of cervical cancer screening in Kenya. Oncologist. 2017;22:173-81.

6. Koster W. Linking two opposites of pregnancy loss: induced abortion and infertility in Yoruba society, Nigeria. Soc Sci Med. 2010;71:1788-95.

7. Otoide VO, Oronsaye F, Okonofua FE. Why Nigerian adolescents seek abortion rather than contraception: evidence from focus-group discussions. Int Fam Plan Perspect. 2001;27:77-81.

8. Schuster S. Abortion in the moral world of the Cameroon Grassfields. Reprod Health Matters. 2005;13:130-8.

9. van Balen $\mathrm{F}, \mathrm{Bos} \mathrm{H}$. The social and cultural consequences of being childless in poor-resource areas. Facts Views Vis ObGyn. 2009;1:106-21.

10. Dierickx S, Rahbari L, Longman C, Jaiteh F, Coene G. 'I am always crying on the inside': a qualitative study on the implications of infertility on women's lives in urban Gambia. Reprod Health. 2018;15.

11. Arksey H, O'Malley L. Scoping studies: towards a methodological framework. Int J Soc Res Methodol. 2005;8:19-32.

12. Langloios EV, Straus SE, Anthony J, King VJ, Tricco AC. Using rapid reviews to strengthen health policy and systems and progress towards universal health coverage. BMJ Glob Health. 2019;4:e001178.

13. Dalaba MA, Stone AE, Krumholz AR, Oduro AR, Phillips JF, Adongo PB. A qualitative analysis of the effect of a community-based primary health care programme on reproductive preferences and contraceptive use among the Kassena-Nankana of northern Ghana. BMC Health Serv Res. 2016;16.

14. Morse JE, Rowen TS, Steinauer J, Byamuqisha J, Kakaire O. A qualitative assessment of Ugandan women's perceptions and knowledge of contraception. Int J Gynecol Obstet. 2014;124:30-3.

15. Capurchande R, Coene G, Schockaert I, Macia M, Meulemans H. 'It is challenging... oh, nobody likes it!': A qualitative study exploring Mozambican adolescents and young adults' experiences with contraception. BMC Womens Health. 2016;16:d.

16. Gebremariam A, Addissie A. Intention to use long acting and permanent contraceptive methods and factors affecting it among married women in Adigrat town, Tigray, northern Ethiopia. Reprod Health. 2014;11.

17. Chitukuta M, Duby Z, Katz A, Nakyanki T, Reddy K, Palanee-Phillips T, et al. Negative rumours about a vaginal ring for HIV-1 prevention in sub-Saharan Africa. Cult Health Sex. 2019;18:1-16.

18. Castle S. Factors influencing young Malians' reluctance to use hormonal contraceptives. Stud Fam Plan. 2003;34:186-99.

19. Cover J, Lim J, Namagembe A, Tumusiime J, Kidwell Drake J, Muntifering CC. Acceptability of contracepive self-injection with DMPA-SC among adolescents in Gulu District, Uganda. Int Perspect Sex Reprod Health. 2017; 43:153-62.

20. Hyttel M, Rasanathan JJK, Tellier M, Taremwa W. Use of injectable hormonal contraceptives: diverging perspectives of women and men, service providers and policymakers in Uganda. Reprod Health Matters. 2012;20:148-57.

21. Krugu JK, Mevissen F, Munkel M, Ruiter R. Beyond love: a qualitative analysis of factors associated with teenage pregnancy among young women with pregnancy experience in Bolgatanga, Ghana. Cult Health Sex. 2017;19:293-307.

22. Muanda M, Gahungu NP, Taub LD, Taub L, Bertrand J. Barriers to modern contraceptive use in Kinshasa, DRC. PLoS ONE Electron Resour. 2016;11: e0167560.

23. Adongo PB, Tabong PTN, Azongo TB, Phillips J, Sheff M, Stone A, et al. A comparative qualitative study of misconceptions associated with contraceptive use in southern and northern Ghana. Front Public Health. 2014;2:137.

24. Ndwamato NN, Ogunbanjo GA. The beliefs and practices of Tshivendaspeaking multiparous women on contraception: a qualitative study. South Afr Fam Pract. 2009:51:340-2.

25. Remes $P$, Selestine V, Changalucha J, Ross D, Wight D, de Sanjose S, et al. A qualitative study of HPV vaccine acceptability among health workers, teachers, parents, female pupils, and religious leaders in Northwest Tanzania. Vaccine. 2012;30:5363-7.

26. Ochako R, Mbondo M, Aloo S, Kaimenyi S, Thompon R, Temmerman M, et al. Barriers to modern contraceptive methods uptake among young women in Kenya: A qualitative study. BMC Public Health. 2015;15. https:// doi.org/10.1186/s12889-015-1483-1.

27. Klinger A, Asgary R. Perceptions and attitudes regarding sexually transmitted infection and family planning among adolescents in northern Madagascar. Women Health. 2017;57:599-613.
28. Chebet JJ, McMahon SA, Greenspan JA, Mosha I, Callaghan-Koru J, Killewo J, et al. 'Every method seems to have its problems'- perspectives on side effects of hormonal contraceptives in Morogoro region, Tanzania. BMC Womens Health. 2015;15:97.

29. Sedlander E, Bingenheimer JB, Thiongo M, Gichangi P, Rimal RN, Edberg M, et al. They destroy the reproductive system': exploring the belief that modern contraceptive use causes infertility. Stud Fam Plan. 2018;49:345-65. https://doi.org/10.1111/sifp.12076.

30. Dhont N, van de Wijgert J, Coene G, Gasarabwe A. Temmerman M. 'Mama and papa nothing': living with infertility among an urban population in Kigali, Rwanda. Hum Reprod 2011;26:623-629.

31. Donkor ES, Naab F, Kussiwaah DY. 'I am anxious and desperate': psychological experiences of women with infertility in the Greater Accra region, Ghana. Fertil Res Pract. 2017;3.

32. Dyer SJ, Abrahams N, Hoffman M, van der Spuy ZM. Infertility in South Africa: Women's reproductive health knowledge and treatmentseeking behaviour for involuntary childlessness. Hum Reprod. 2002;17: 1657-62.

33. Hess RF, Ross R, Gililland JL Jr. Infertility, psychological distress, and coping strategies among women in Mali, West Africa: a mixed-methods study. Afr J Reprod Health. 2018;22:60-72.

34. Hollos M, Larsen U. Motherhood in sub-Saharan Africa: the social consequences of infertility in an urban population in northern Tanzania. Cult Health Sex. 2008;10:159-73.

35. Fledderjohann JJ. 'Zero is not good for me': implications of infertility in Ghana. Hum Reprod. 2012;27:1383-90.

36. Mabasa LF. The psychological impact of infertility on African women and their families. Dissertation. University of South Africa. 2005. http://hdl.handle. net/10500/974. Accessed 12 Nov 2019.

37. Runganga $\mathrm{AO}$, Sundhry J, Aggleton P. Culture, identity and reproductive failure in Zimbabwe. Sexualties. 2001;4:315-32.

38. Tabong PT-N, Adongo PB. Infertility and childlessness: a qualitative study of the experiences of infertile couples in northern Ghana. BMC Pregnancy Childbirth. 2013;13.

39. Tabong PT-N, Adongo PB. Understanding the social meaning of infertility and childbearing: a qualitative study of the perception of childbearing and childlessness in northern Ghana. PLOS ONE Electron Resour. 2013:8:e54429.

40. Naab F, Kwashie AA. 'I don't experience any insults, but my wife does': the concerns of men with infertility in Ghana. South Afr J Obstet Gynaecol. 2018:24:45-8.

41. Kamau PM. The experiences of infertility among married Kenyan women. Dissertation. Western Michigan University. 2011. https://scholarworks.wmich. edu/dissertations/425. Accessed 12 Nov 2019.

42. Gerrits T. Social and cultural aspects of infertility in Mozambique. Patient Educ Couns. 1997;31:39-48.

43. Feldman-Savelsberg P. Plundered kitchens and empty wombs: fear of infertility in the Cameroonian grassfields. Soc Sci Med. 1994;39:463-74

44. Upton RL, Dolan EM. Sterility and stigma in an era of HIV/AIDS: narratives of risk assessment among men and women in Botswana. Afr J Reprod Health. 2011;15:95-102.

45. Parrott FR. 'At the hospital I learnt the truth': diagnosing male infertility in rural Malawi. Anthropol Med. 2014:21:174-88.

46. Polis $C B$, Hussain $R$, Berry $A$. There might be blood: a scoping review on women's responses to contraceptive-induced menstrual bleeding changes. Reprod Health. 2018;15:114.

47. Ackerson K, Zielinski R. Factors influencing use of family planning in women living in crisis affected areas of sub-Saharan Africa: a review of the literature. Midwifery. 2017;54:35-60.

48. Dyer SJ, Patel M. The economic impact of infertility on women in developing countries - a systematic review. Facts Views Vis Obgyn. 2012:4:102-9.

49. Bayoumi RR, van der Poel S, El Samani EZ, Boivin J. An evaluation of comprehensiveness, feasibility and acceptability of a fertility awareness educational tool. Reprod Biomed Soc Online. 2018;6:10-21.

50. Marston C, Francis S. Neglect of STIs and infertility undermines family planning programmes. BMJ Sex Reprod Health 2019;Sep 26:pii: bmjsrh-2018-200270.

51. d'Arcanques CM, Ba-Thike K, Say L. Expanding contraceptive choice in the developing world: lessons from the Lao People's Democratic Republic and the Republic of Zambia. Eur J Contracept Reprod Health Care. 2013;18:421-34 
52. World Health Organisation. Sexual health and its linkages to reproductive health: an operational approach. Geneva, Switzerland: Department of Reproductive Health and Research, World Health Organisation. 2017. https:// www.who.int/reproductivehealth/publications/sexual_health/sh-linkages-rh/ en/ Accessed 12 Nov 2019.

53. Ajayi Al, Adeniyi OV, Akpan W. Use of traditional and modern contraceptives among childbearing women: findings from a mixed methods study in two southwestern Nigerian states. BMC Public Health. 2018;18:604

\section{Publisher's Note}

Springer Nature remains neutral with regard to jurisdictional claims in published maps and institutional affiliations.

Ready to submit your research? Choose BMC and benefit from:

- fast, convenient online submission

- thorough peer review by experienced researchers in your field

- rapid publication on acceptance

- support for research data, including large and complex data types

- gold Open Access which fosters wider collaboration and increased citations

- maximum visibility for your research: over $100 \mathrm{M}$ website views per year

At $\mathrm{BMC}$, research is always in progress.

Learn more biomedcentral.com/submissions 